\title{
Predictors of underweight in children under-five years in Ghana
}

\author{
Evelyn Acquah ${ }^{1}$, Eugene K. M. Darteh ${ }^{2}$, Hubert Amu, ${ }^{2,3}$ and Daniel K. A. Adjei ${ }^{4}$ \\ Ghana Med J 2019; 53(1): 71-78 http://dx.doi.org/10.4314/gmj.v53i1.11
}

\author{
${ }^{1}$ Institute of Health Research, University of Health and Allied Sciences, Ho, Ghana \\ ${ }^{2}$ Department of Population and Health, University of Cape Coast, Cape Coast, Ghana \\ ${ }^{3}$ Department of Population and Behavioural Sciences, School of Public Health, University of Health and Allied \\ Sciences, Hohoe, Ghana. \\ ${ }^{4}$ JMK Consulting Limited, Accra, Ghana
}

Corresponding author: Hubert Amu

E-mail: hamu@uhas.edu.gh

Conflict of interest: None declared

\section{SUMMARY}

Background: Underweight is a key indicator of malnutrition in children and results in long term effects such as abnormalities in physical and mental health, behavioural problems, and low educational achievement.

Objective: Using the conceptual framework for child malnutrition by the United Nations Children's Fund, we examined the predictors of underweight in children under five years in Ghana.

Methods: This cross-sectional study made use of data from the 2014 Ghana Demographic and Health Survey. A total of 2720 children were included in the analysis. Descriptive and inferential statistics comprising frequency, percentage, chi-square, and binary logistic regression were used in analysing the data.

Results: The prevalence of underweight was $11 \%$. Age, wealth status, mother's education, region, ethnicity, household toilet facility, the source of drinking water, the incidence of diarrhoea, and subscription to health insurance significantly predicted underweight in the children. The risk of being underweight was higher in females than males $(\mathrm{OR}=1.04,95 \% \mathrm{CI}=0.81-1.34)$. This was, however, not statistically significant. The probability of being underweight also declined significantly with mother's level of education.

Conclusion: Our findings underscore the need for the Ghana Health Service and other health sector stakeholders to apportion interventions with a focus on improving complementary feeding, poverty alleviation, and health status of children.

Funding: No funding was received for the study

Keywords: malnutrition, underweight, predictors, children, under five, Ghana

\section{INTRODUCTION}

Children under five years of age remain the most vulnerable group to malnutrition and micronutrients deficiency. ${ }^{1}$ Globally, about 5.9 million children under five die every year and $45 \%$ of these deaths are linked to malnutrition. ${ }^{2}$ Underweight is a key indicator of malnutrition in children and results in long term effects such as abnormalities in physical and mental health, behavioural problems, and low educational achievement. $^{3,4}$

Children whose weight for age measures are below minus two standard deviations (-2SD) from the median of the reference population are considered underweight while those with measures below minus three standard deviations (-3SD) are severely underweight. ${ }^{4}$ The international community has strengthened its commitment to reducing childhood underweight by implementing interventions including exclusive breastfeeding and nutritionally adequate diets for children less than five years. ${ }^{5}$ As a result of such interventions, the global prevalence of underweight in children declined from $25 \%$ in 1990 to $14 \%$ in 2015 . This decline was, however, not enough to achieve the Millennium Development Goal (MDG) target set to halve underweight by $2015 .{ }^{3}$ Ghana, on the other hand, has been able to reduce the prevalence of underweight in children under five from 23\% in 1993 to the current prevalence of $11 \%{ }^{4}$

Although this means the MDGs target has been achieved, more effort is needed to achieve the second target of the Sustainable Development Goal two, which requires the country to end all forms of malnutrition by the year $2030 .^{6}$ 
Even though some studies have been conducted in the past on underweight in children under five in Ghana, $, 8,8$ the only study conducted with nationally representative data and investigated the predictors of underweight in children was by Amugsi, Mittelmark and Lartey ${ }^{10}$ in a trend analysis using data from the 1993, 1998, 2003, and 2008 Ghana Demographic and Health surveys (GDHS). A lot of changes have occurred regarding the nutritional status of children under five since the 2008 GDHS including the conduct of the 2014 GDHS which made some different findings from what was reported by the previous versions. While there are numerous sociodemographic and economic factors included in the demographic and health survey reports which are possible predictors of underweight in children, Amugsi et al. ${ }^{10}$ focused only on sex, age, mother's education, urban/rural residence, region of residence, and wealth status.

In addition to the variables examined by Amugsi et al. ${ }^{10}$, we examined the influence of mother's age, ethnicity, source of drinking water, incidence of diarrhoea, toilet facility, and subscription to the National Health Insurance Scheme (NHIS) on the incidence of underweight in children at both bivariate and multivariate levels. Using data from the nationally representative 2014 Ghana Demographic and Health Survey, our study is relevant in adding to the literature by unearthing the predicting effects of these variables which were not considered by Amugsi et al. ${ }^{10}$ and informing policy decisions in the light of finding made.

\section{Theoretical issues}

The selection of possible determinants of underweight was guided by the available data in the 2014 GDHS dataset and conceptual framework for child malnutrition developed by the United Nations Children's Fund (UNICEF). ${ }^{11}$ The socio-economic and demographic variables available within the GDHS dataset fit appropriately with the underlying causal level of the framework despite the broad nature of the conceptual framework for the causes of child malnutrition. We, therefore, concentrated on examining the underlying determinants of childhood underweight using the conceptual framework.

According to the conceptual framework, access to quality nutrition is influenced directly by food intake, caring practices, and health environment and services. ${ }^{11}$ The resources essential for gaining access to food are food production and income for food purchases. The household economic status measured by the household wealth index was used as a substitute for income and household access to food. This is because the GDHS dataset did not have direct food security (per capita energy intake), income, or expenditure and price variables.

The second underlying determinant which is care is explained by variables such as time breastfeeding was initiated by the mother, whether a child was given complementary feeding, whether the mother gave birth to the child in a health facility, and whether the mother visited antenatal care throughout pregnancy. ${ }^{11}$

Such care is shown by how the caregiver controls economic resources, her independence in decisionmaking, and the state of her physical and mental health. All of these resources for care are influenced by the caregiver's knowledge, beliefs, and maturity. ${ }^{12}$ Ethnicity, mother's age, and level of education were used to represent this aspect of care.

Health environment and services, which is the third underlying determinant of child nutritional status, is generally measured by accessibility to potable water, improved sanitation, access to healthcare, environmental care, and shelter. ${ }^{11}$ Source of drinking water, type of toilet facility, the incidence of diarrhoea, and NHIS subscription were used to represent health, environment, and services. Age, sex, and region of residence were included to examine the variations in the different age groups and sex as well as the spatial variation of childhood underweight.

\section{METHODS}

Our study made use of data from the children recode file of the 2014 GDHS. The GDHS is a nationally representative survey which is designed and crosssectionally conducted in the country every five years. ${ }^{13}$ The 2014 version was, however, conducted six years after the 2008 version. The survey is carried out by the Ghana Statistical Service and the Ghana Health Service with technical assistance from ICF International through the DHS Programme. Data for this study were requested from the Measure DHS website and approval was given to download it online (http://www.measuredhs.com). The Ghana Health Service Ethical Review Committee in Accra gave ethical approval for the study protocol of the 2014 GDHS.

The 2014 version of the GDHS was conducted with a sample size of 12,831 households chosen nationally. A two-stage sampling approach was used in recruiting participants for the study. The first stage involved choosing sample points (clusters) consisting of enumeration areas (EAs) delineated for the country's 2010 population and Housing Census (PHC). The sampling frame used for the 2014 GDHS is an updated 
frame from the 2010 Ghana Population and Housing Census (PHC) provided by the Ghana Statistical Service. In all, 427 clusters were chosen from the master sampling frame. ${ }^{4}$

The second stage involved the systematic sampling of about 30 of the households from each cluster. Finally, 12,821 households were selected for the survey.

Height and weight measurements of children under the age of five years were taken in the subsample of households selected for the male survey and biomarker collection, regardless of whether the children's mothers were interviewed in the survey. The number of occupied households successfully interviewed was 11,835, yielding a household response rate of $99 \%$.

In the households selected for individual interviews, a total of 9,656 eligible women were identified; interviews were completed with 9396 of these women, yielding a response rate of $97 \%$. In the same households, a total of 4609 eligible men were identified and interviews were completed with 4,388 of these men, yielding a response rate of $95 \%$. There were 2,895 children under age five whose height and weight measurements were taken. ${ }^{4}$

Data on the weight-for-age of children were collected by measuring the weight of all children less than five years of age. SECA 878 digital scale, designed and manufactured under the guidance of the United Nations Children's Fund (UNICEF) was used to collect the data on weight. All data were entered twice for $100 \%$ verification. ${ }^{4}$ A total of 2720 children under five years who had valid anthropometric data were included in our study. In the DHS data, a z-score is given for the child's weight relative to the age. It is defined as the number of standard deviation units from the median weight in children of that age in an international reference population.

Children with z-scores of -201 to -572 for weight-for-age were considered Underweight while those with z-scores of -200 to 385 were considered not underweight. The outcome variable for this study was Underweight. Underweight was coded as $1=$ Underweight and $0=$ not Underweight. Age, sex, region, ethnicity, mother's level of education, wealth status, the source of drinking water, toilet facility, mother's age, the incidence of diarrhea, and health insurance subscription were the explanatory variables. Age in months was group into 0-5, 6-11, 1223, 24-35, 36-47, and 48-59 months. Educational level was put into four categories; no education, primary education, middle /Junior Secondary School (JHS), and Senior Secondary School or higher education.
Region of residence was made up of the ten regions of Ghana; Ashanti, Western, Eastern, Volta, Northern, Brong Ahafo, Central, Greater Accra, Upper East, and Upper West. Ethnicity was recoded into seven ethnic groups namely; Akan, Ga/Dangme, Ewe, Guan, MoleDagbani, Grusi/Gurma/Mande, and Others. Sex was categorized as male and female. Wealth status was constructed from household assets or consumer items such as ownership television, bicycle, or car, as well as dwelling characteristics, such as a source of drinking water, sanitation facilities, and type of flooring material. Wealth index was created in three steps. In the first step, a subset of indicators common to urban and rural areas was used to create wealth scores for households in both urban and rural areas. In the second step, separate factor scores are produced for households in urban and rural areas using area-specific indicators. The third step combines the separate area-specific factor scores to produce a nationally applicable combined wealth index by adjusting area-specific scores through a regression on the common factor scores.

The resulting combined wealth index had a mean of zero and a standard deviation of one. Once the index was computed, national-level wealth quintiles (from lowest to highest) were obtained by assigning the household score to each de jure household member. ${ }^{4}$ It was divided into five categories: poorest, poorer, middle, richer, and richest. Source of drinking water was recoded into improved and unimproved water. The GDHS classifies water sources comprising sachet, bottled water, pipe water, borehole, spring water, and protected well as improved sources.

Unprotected well, tanker truck, river/stream, and dam/lake/pond/canal/irrigation canal are, however, classified as unimproved sources. ${ }^{4}$ Type of toilet facility was recoded as improved and unimproved. Improved toilet facilities comprise flush to pipe sewage system, flush to septic tank, flush to pit latrine, ventilated improved pit latrine, and pit latrine with slab as improved sources of toilet facility while pit latrine without slab/open pit, bucket, no facility/bush as unimproved source. ${ }^{4}$ The incidence of diarrhea was recoded as yes for diarrhoea in the two weeks preceding the survey and no diarrhoea in the two weeks preceding the survey for no. Subscription to the NHIS was also recoded as no and yes.

Descriptive statistics (frequencies and percentages) were used to present the socio-demographic and economic characteristics of the children. Chi-square and binary logistic regression were, however, used to examine the relationship between explanatory variables and the outcome variable. The regression model was a multivariate analysis of the effects of all the explanatory 
variables on the outcome variables. The formulae behind the model is available from Hyötyniemi. ${ }^{14}$ Binary logistic regression was used because the outcome variable was dichotomous. The acceptable level of significance was $\mathrm{p}<0.05$.

To make the findings representative and offset the effects of under and over reporting which are characteristic of nationwide surveys, both the descriptive and inferential analyses were weighted. All analyses were conducted using STATA version 12.

\section{RESULTS}

Table 1 presents results of the background characteristics of the 2720 children included in the study. We found that $21.5 \%$ of the children were aged 12-23 months while $10.7 \%$ were aged $6-11$ months.

Males were more (52.4\%) than Females (47.6\%) and a comparative majority were resident in the Ashanti Region (17.5\%). Children from the Akan ethnic group were the comparative majority (48.3\%) while those from 'others' constituted $1.7 \%$. Children whose mothers had middle/JSS education formed the comparative majority (38.9\%) and those whose mothers had secondary or higher education had the least representation (12.7\%).

A comparative majority of the children were from poorest households (22.9\%) while those from the richest households constituted $18.1 \%$. Most of the children were from households with improved sources of drinking water $(86.1 \%)$ and toilet facilities $(66.7 \%)$ respectively. The ages of the children's mothers ranged from 15 to 59 years, with a comparative majority being in their early $30 \mathrm{~s}(25.5 \%)$. Most of the children were breastfed immediately after birth $(50.7 \%)$ while $10.7 \%$ were breastfed 1-14 days after birth. Most of the children (88.3\%) did not have episodes of diarrhoea two weeks prior to the survey. Children who were registered with the NHIS were also more (68.3\%) than those who were not registered $(31.7 \%)$ (Table 1$)$.

Table 2 presents the proportions and binary logistic regression analysis of the determinants of underweight in the children surveyed. Overall, $11 \%$ of children were underweight. The incidence of underweight was highest in children aged 24-36 months (14.2\%) while those aged 0-5 months had the lowest proportion of underweight $(4.2 \%)$.

Females also recorded a slightly higher proportion of underweight $(11.2 \%)$ compared to males $(10.5 \%)$. By wealth status, underweight was lowest in children from the richest households $(5.7 \%)$, but highest in those from the poorest households (15.3\%). The incidence of underweight declined with the level of education of mother; none (14.7\%), primary (12\%), middle/JHS (9.5\%), and secondary or higher (4.6). Underweight was highest in children of mothers who were in their late teens $(20.1 \%)$.

Table 1 Background characteristics of children

\begin{tabular}{|c|c|c|}
\hline Variable & Category & $\underline{\mathbf{n}(\%)}$ \\
\hline \multicolumn{3}{|l|}{ Age of child in months [N=2720] } \\
\hline & $0-5$ & $310(11.4)$ \\
\hline & $6-11$ & 291(10.7) \\
\hline & $12-23$ & $584(21.5)$ \\
\hline & $24-35$ & $541(19.9)$ \\
\hline & $36-47$ & $514(18.9)$ \\
\hline & $48-59$ & $480(17.6)$ \\
\hline \multicolumn{3}{|l|}{ Sex $[N=2720]$} \\
\hline & Males & $1,424(52.4)$ \\
\hline & Females & $1,296(47.6)$ \\
\hline \multicolumn{3}{|l|}{ Region $[\mathrm{N}=2720]$} \\
\hline & Western & $287(10.6)$ \\
\hline & Central & $315(11.5)$ \\
\hline & Greater Accra & $410(15.1)$ \\
\hline & Volta & $202(7.4)$ \\
\hline & Eastern & $244(8.9)$ \\
\hline & Ashanti & $477(17.5)$ \\
\hline & Brong Ahafo & $255(9.4)$ \\
\hline & Northern & $347(12.8)$ \\
\hline & Upper East & $110(4.1)$ \\
\hline & Upper West & $73(2.7)$ \\
\hline \multicolumn{3}{|l|}{ Ethnicity [N=2720] } \\
\hline & Akan & $1,314(48.3)$ \\
\hline & $\mathrm{Ga} /$ Dangme & $151(5.6)$ \\
\hline & Ewe & $348(12.8)$ \\
\hline & Guan & $61(2.2)$ \\
\hline & Mole-Dagbani & $467(17.2)$ \\
\hline & $\begin{array}{l}\text { Grusi/Gurma/Mand } \\
\mathrm{e}\end{array}$ & $332(12.2)$ \\
\hline & Others & $47(1.7)$ \\
\hline \multicolumn{3}{|l|}{ Mother's education [N=2720] } \\
\hline & No education & $782(28.8)$ \\
\hline & Primary & $534(19.6)$ \\
\hline & Middle/JHS & $1,058(38.9)$ \\
\hline & Secondary or higher & $346(12.7)$ \\
\hline \multicolumn{3}{|l|}{ Wealth Status $[N=2720]$} \\
\hline & Poorest & $625(22.9)$ \\
\hline & Poorer & $551(20.3)$ \\
\hline & Middle & $556(20.4)$ \\
\hline & Richer & $497(18.3)$ \\
\hline & Richest & $491(18.1)$ \\
\hline \multicolumn{3}{|l|}{ Source of drinking water [N=2659] } \\
\hline & Improved & $2,290(86.1)$ \\
\hline & Unimproved & $369(13.9)$ \\
\hline \multicolumn{3}{|l|}{ Toilet facility [N=2659] } \\
\hline & Improved & $1,772(66.7)$ \\
\hline & Unimproved & $887(33.3)$ \\
\hline \multicolumn{3}{|l|}{ Mother's age [N=2720] } \\
\hline & $15-19$ & $97(3.6)$ \\
\hline & $20-24$ & $463(17.0)$ \\
\hline & $25-29$ & $652(24.0)$ \\
\hline & $30-34$ & $695(25.5)$ \\
\hline & $35-39$ & $518(19.0)$ \\
\hline & $40-44$ & $223(8.2)$ \\
\hline & $45-59$ & $73(2.7)$ \\
\hline
\end{tabular}




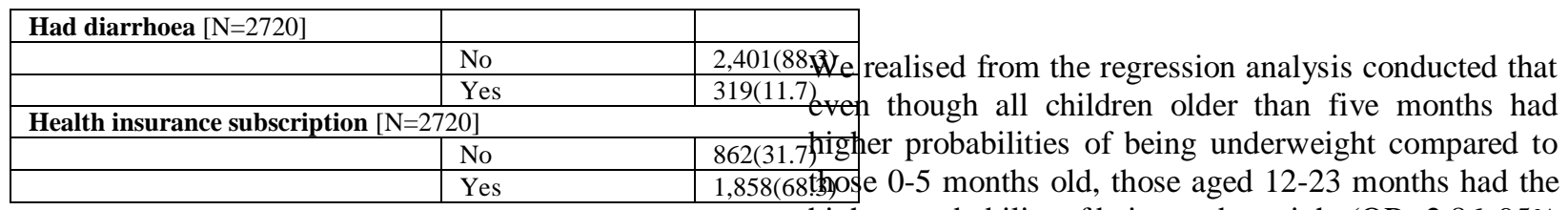

Source: Computed from 2014 GDHS dataset NA=Not Applicable

The proportion of underweight was highest in children in the Northern Region (19.8\%), but lowest in those in the Brong Ahafo region (5.1\%). Children belonging to the $\mathrm{Ga} /$ Dangme ethnic group $(5.3 \%)$ recorded the least proportion of underweight while Mole-Dagbanis had the highest (14.1\%). Underweight was also higher in children from households with unimproved toilet facilities (13.5\%) and sources of drinking water (13.1\%) compared to those with improved toilet facilities $(10.5 \%)$ and sources of drinking water $(9.8 \%)$ respectively.

More children who had diarrhoea two weeks prior to the survey, were underweight (13.7\%) compared to those who did not have diarrhoea $(10.5 \%)$. The incidence of underweight children was also lower in children who were subscribed to the national health insurance scheme (9.4\%) compared to those who were not subscribers $(13.9 \%)$. Age, wealth status, mother's education, region, ethnicity, household toilet facility, the source of drinking water, the incidence of diarrhoea, and subscription to health insurance significantly predicted underweight in the children (Table 2). highest probability of being underweight $(\mathrm{OR}=2.86,95 \%$ $\mathrm{CI}=1.61-5.07, \mathrm{p}<0.001)$. The risk of being underweight was higher in females than males $(\mathrm{OR}=1.04,95 \%$ $\mathrm{CI}=0.81-1.34$ ). The probability of being underweight also declined with mother's level of education. The likelihood of being underweight was also highest in children whose mothers were in their late teens. Though not statistically significant, Children in the Northern Region were 1.39 times more likely to be underweight compared to children in the Western region. Children in households with unimproved sources of drinking water were also more likely to be underweight than those with improved sources $(\mathrm{OR}=1.17,95 \% \mathrm{CI}=0.83-1.64)$. The risk of being underweight was higher for those children who had diarrhoea two weeks prior to the survey compared to those who had no diarrhoea with the same period $(\mathrm{OR}=1.27,95 \% \mathrm{CI}=0.89-1.82)$. The probability of being underweight was also lower in children who were subscribed to health insurance compared to those who were not subscribed $(\mathrm{OR}=0.72,95 \% \mathrm{CI}=0.55-0.95$, $\mathrm{p}<0.01)$.

Table 2 Bivariate and multivariate analyses for the predictors of underweight in children under five years of age

\begin{tabular}{|c|c|c|c|c|}
\hline \multirow[t]{2}{*}{ Variables } & \multirow[t]{2}{*}{ Category } & \multirow{2}{*}{$\begin{array}{l}\text { Bivariate } \\
\mathrm{n}(\%)\end{array}$} & \multicolumn{2}{|c|}{ Multivariate } \\
\hline & & & OR & $95 \% \mathrm{CI}$ \\
\hline \multicolumn{5}{|c|}{ Proportion of children underweight } \\
\hline & All & $295(11)$ & NA & NA \\
\hline \multicolumn{5}{|c|}{ Age of child in months $\left(\right.$ Pearson $\left.x^{2}=23.0675 ; p \leq 0.001\right)$} \\
\hline & $0-5$ & $13(4.2)$ & 1 & {$[1,1]$} \\
\hline & $6-11$ & $38(12.9)$ & $2.57 * * *$ & {$[1.37-4.81]$} \\
\hline & $12-23$ & $78(13.3)$ & $2.86^{* * * *}$ & {$[1.61-5.07]$} \\
\hline & $24-35$ & $77(14.2)$ & $2.78^{* * *}$ & {$[1.55-4.94]$} \\
\hline & $36-47$ & $59(11.5)$ & $2.08^{* *}$ & {$[1.15-3.77]$} \\
\hline & $48-59$ & $31(6.4)$ & 1.63 & {$[0.88-3.02]$} \\
\hline \multicolumn{5}{|c|}{ Sex $\left(\right.$ Pearson $\left.x^{2}=0.2598 ; p>0.05\right)$} \\
\hline & Male & $150(10.5)$ & 1 & {$[1-1]$} \\
\hline & Female & $145(11.2)$ & 1.04 & {$[0.81-1.34]$} \\
\hline \multicolumn{5}{|c|}{ Wealth Status (Pearson $\left.\mathrm{x}^{2}=37.0571 ; \mathrm{p} \leq 0.001\right)$} \\
\hline & Poorest & $95(15.3)$ & 1 & {$[1-1]$} \\
\hline & Poorer & $75(13.6)$ & 0.90 & {$[0.61-1.32]$} \\
\hline & Middle & $41(7.4)$ & $0.57 * *$ & {$[0.35-0.91]$} \\
\hline & Richer & $56(11.2)$ & 0.70 & {$[0.41-1.18]$} \\
\hline & Richest & $28(5.7)$ & $0.40 * *$ & {$[0.20-0.83]$} \\
\hline \multicolumn{5}{|c|}{ Mother's Education (Pearson $\left.x^{2}=33.5237 ; p \leq 0.001\right)$} \\
\hline & None & $115(14.7)$ & 1 & {$[1-1]$} \\
\hline & Primary & $64(12.0)$ & 0.84 & {$[0.58-1.22]$} \\
\hline & Middle/JSS & $101(9.5)$ & $0.61 * *$ & {$[0.41-0.91]$} \\
\hline & Secondary or higher & $16(4.6)$ & $0.47 * *$ & {$[0.24-0.91]$} \\
\hline \multicolumn{5}{|c|}{ Mother's Age $\left(\right.$ Pearson $x^{2}=12.0487 p>0.05$ ) } \\
\hline & $15-19$ & $19(20.1)$ & 1 & {$[1-1]$} \\
\hline & $20-24$ & $51(11.0)$ & $0.51 * *$ & {$[0.27-0.96$} \\
\hline
\end{tabular}




\begin{tabular}{|c|c|c|c|c|}
\hline \multirow[t]{2}{*}{ Variables } & \multirow[t]{2}{*}{ Category } & \multirow{2}{*}{$\begin{array}{l}\text { Bivariate } \\
\mathrm{n}(\%)\end{array}$} & \multicolumn{2}{|c|}{ Multivariate } \\
\hline & & & $\mathrm{OR}$ & $95 \% \mathrm{CI}$ \\
\hline & $25-29$ & 71(10.9) & $0.55^{* *}$ & {$[0.29-0.98]$} \\
\hline & $30-34$ & $77(11.4)$ & $0.54 * *$ & {$[0.29-0.98]$} \\
\hline & $35-39$ & $44(8.6)$ & $0.37 * * *$ & {$[0.19-0.74]$} \\
\hline & $40-44$ & $24(10.7)$ & $0.51 * *$ & {$[0.28-0.97]$} \\
\hline & $45-49$ & $9(11.7)$ & 0.48 & {$[0.19-1.23]$} \\
\hline \multicolumn{5}{|c|}{ Region $\left(\right.$ Pearson $\left.x^{2}=38.6404 ; p \leq 0.001\right)$} \\
\hline & Western & $30(10.3)$ & 1 & {$[1-1]$} \\
\hline & Central & 41(13.1) & 0.98 & {$[0.57-1.69]$} \\
\hline & Greater Accra & $33(8.0)$ & 1.01 & {$[0.49-2.09]$} \\
\hline & Volta & $19(9.5)$ & 0.81 & {$[0.37-1.74]$} \\
\hline & Eastern & $20(8.4)$ & 0.66 & {$[0.35-1.27]$} \\
\hline & Ashanti & $47(10.0)$ & 0.79 & {$[0.43-1.45]$} \\
\hline & Brong Ahafo & $13(5.1)$ & 0.43 & {$[0.23-0.80]$} \\
\hline & Northern & $69(19.8)$ & 1.39 & {$[0.73-2.63]$} \\
\hline & Upper East & $13(12.0)$ & 0.89 & {$[0.43-1.82]$} \\
\hline & Upper West & $10(13.2)$ & 0.89 & {$[0.43-1.84]$} \\
\hline \multicolumn{5}{|c|}{ Ethnicity $\left(\right.$ Pearson $\left.\mathrm{x}^{2}=14.3410 ; \mathrm{p} \leq 0.05\right)$} \\
\hline & Akan & $129(9.8)$ & 1 & {$[1-1]$} \\
\hline & $\mathrm{Ga} /$ Dangme & $8(5.3)$ & 0.46 & {$[0.17-1.23]$} \\
\hline & Ewe & $37(10.7)$ & 0.75 & {$[0.40-1.41]$} \\
\hline & Guan & $4(6.1)$ & 0.56 & {$[0.22-1.46]$} \\
\hline & Mole Dagbani & $69(14.1)$ & 0.80 & {$[0.47-1.36]$} \\
\hline & Grusi/Gurma/Mande & $46(13.9)$ & 0.69 & {$[0.39-1.21]$} \\
\hline & Others & $5(10.8)$ & 0.94 & {$[0.34-2.60]$} \\
\hline \multicolumn{5}{|c|}{ Toilet facility $\left(\right.$ Pearson $\left.\mathrm{x}^{2}=7.9098 ; \mathrm{p} \leq 0.01\right)$} \\
\hline & Improved & $174(9.8)$ & 1 & {$[1-1]$} \\
\hline & Unimproved & $116(13.1)$ & 0.86 & {$[0.62-1.19]$} \\
\hline \multicolumn{5}{|c|}{ Source of drinking water $\left(\right.$ Pearson $\left.\mathrm{x}^{2}=8.2313 ; \mathrm{p} \leq 0.01\right)$} \\
\hline & Improved & $240(10.5)$ & 1 & {$[1-1]$} \\
\hline & Unimproved & $50(13.5)$ & 1.17 & {$[0.83-1.64]$} \\
\hline \multicolumn{5}{|c|}{ Had diarrhoea $\left(\right.$ Pearson $\left.\mathrm{x}^{2}=3.971 ; \mathrm{p} \leq 0.05\right)$} \\
\hline & No & $251(10.5)$ & 1 & {$[1-1]$} \\
\hline & Yes & $44(13.7)$ & 1.27 & {$[0.89-1.82]$} \\
\hline \multicolumn{5}{|c|}{ Health insurance subscription $\left(\right.$ Pearson $x^{2}=13.1564 ; p \leq 0.001$ ) } \\
\hline & No & $120(13.9)$ & 1 & {$[1-1]$} \\
\hline & Yes & $175(9.4)$ & $0.72^{* * *}$ & {$[0.55-0.95]$} \\
\hline
\end{tabular}

Source: Computed from 2014 GDHS dataset. ***p $<0.001$, **p $<0.01,{ }^{*} \mathrm{p}<0.05$ NA=Not Applicable

\section{DISCUSSION}

In the multivariate analysis, Age, wealth status, mother's age, level education and subscription to health insurance significantly predicted underweight in the children. It was found that children aged 12-23 months had the highest odds of underweight. This can be attributed to the fact that most children at this age have begun to walk thus, exerting more energy and need adequate dietary intake to get the optimal weight for their age. The finding of the study is consistent with the studies of Black et al. ${ }^{15}$ and Babatunde and Qaim ${ }^{16}$ who found age to be significantly related to underweight.

A finding of our study shows a significant relationship between underweight and wealth status; the odds of underweight was lower in children from richest wealth quintile compared to children from poorest wealth quintile. Though wealth is not directly proportional to food intake and availability of food does not guarantee balance diet, sufficient resources accessible to a household gives it a high purchasing power to afford quality and nutritious foods for their children. This finding corroborates previous studies which posited that sufficient resources accessible to a household influence the household's access to nutritious foods which can influence the risk of being underweight ${ }^{17}$ and is thus congruent with postulations of the conceptual framework for the causes of child malnutrition. ${ }^{11}$

The finding of the study shows that underweight in children decreases as mother's level of education increases. It indicated that women who had secondary or higher education were less likely to have underweight children compared to women with no level of education. The result confirms studies that have shown that educated mothers tend to have well-nourished children. ${ }^{18,19}$ It could be explained by the fact that literate mothers adopt enhanced behaviours linked to child health care, feeding and eating practices which may eventually affect the nutritional status of children. ${ }^{20}$ 
Mother's age was found to be significantly related to childhood underweight. It was observed that children with mothers in their late teens had the highest probability of being underweight. This confirms postulations of a previous study that mothers that give birth at a very early age are likely to have children with underweight. ${ }^{21}$

This may be as a result of the fact that young mothers require a lot of nutrition to fully grow into adults. ${ }^{17}$

The little or no experience of such mothers in caring for children could also be a factor. The findings showed a significant association between subscription of health insurance and underweight in children. Though subscription to health insurance is not equitable to utilisation, it however, increases access to health care compared to uninsured children as found in previous studies. $^{22,23}$

Our findings underscore the need for the Ghana Health Service and other health sector stakeholders (including health facilities and Non-Governmental Organisations) to scale up interventions intended to reduce childhood underweight with focus on poverty alleviation, e providing support for girls to attain higher level of education, increasing age at childbirth and subscription to health insurance. in This research was quantitative in nature. Further studies could be qualitatively conducted to focus on reasons for the variations observed in the probability of being underweight in children under five in Ghana.

\section{Limitations}

Despite the important finding made, the limitations of the study are worth noting. This study is limited by its crosssectional nature and hence causal inferences cannot be made. We were also not able to account for unobserved heterogeneity. The study, however, has some compelling strengths. These include the large sample resulting in the representativeness of the sample which gives sufficient power to the study and enhances its generalisability.

\section{CONCLUSION}

We examined the predictors of underweight in children under five in Ghana using data from the 2014 Ghana Demographic Health Survey. The proportion of underweight in children in the country was found to be $11 \%$. Age, wealth status, mother's age, level education and subscription to health insurance significantly predicted underweight in the children. The implication of the findings is that the country may not be able to achieve the sustainable development goal target of ending under nutrition by the year 2030 if interventions geared towards fighting undernutrition in children are not scaled up.

\section{ACKNOWLEDGEMENT}

The authors would like to thank IFC International for granting the permission to use the data.

\section{REFERENCES}

1. Chege PM, Kuria EN. Relationship Between Nutrition Knowledge of Caregivers and Dietary Practices of Children Under Five in Kajiado County, Kenya. Women's Health Bulltn. 2017;4(3): e43820.

2. World Health Organisation. Children, reducing mortality: Fact sheet; 2016. Retrieved from http://www.who.int/mediacentre/factsheets/fs 178/e n/ On 05/01/2018

3. United Nations. The millennium development goals report. New York: United Nations; 2015.

4. Ghana Statistical Service (GSS), Ghana Health Service (GHS) and ICF International. Ghana demographic and health survey 2014. Maryland: GSS, GHS and ICF International; 2015.

5. World Health Organisation. Comprehensive implementation plan on maternal, infant and young child nutrition. Geneva: World Health Organisation; 2014.

6. United Nations Development Programme. Sustainable development goals; 2015 Retrieved from

http:/www.undp.org/content/undp/en/home/mdgove rview/post-2015-development-agenda/goal-2.html On 04/01/2018.

7. Mensah C. Maternal factors and the nutritional status of children under five years in the AsanteAkim North Municipality, Ghana. (Master's Thesis), Kwame Nkrumah University of Science and Technology, Kumasi, Ghana, 2014

8. Nyarko LV. Determinants of malnutrition in children less than five years in the Bosomtwe District, Ashanti, Ghana. (Master's Thesis), Kwame Nkrumah University of Science and Technology, Kumasi, Ghana; 2008.

9. Naabah SN. Management of severe acute malnutrition in children under five in the Tolon District. (Master's Thesis), University of Ghana, Accra, Ghana; 2016.

10. Amugsi DA, Mittelmark MB, Lartey A. An analysis of socio-demographic patterns in child malnutrition trends using Ghana demographic and health survey data in the period 1993-2008. BMC Pub. Health. 2013; 13: 960.

11. United Nations Children's Fund. Strategy for improved nutrition of children and women in developing countries. New York: UNICEF; 1990.

12. Smith LC, Haddad L. Explaining child malnutrition in developing countries: A cross-country analysis. Washington, D.C: International Food Policy Research Institute; 2000. 
13. Dickson KS, Adde KS, Amu H. What Influences where they give birth? Determinants of place of delivery among women in rural Ghana". IJRMED. 2016; 1:1-8.

14. Hyötyniemi H. Multivariate regression: Techniques and tools. Helsinki University of Technology; 2001.

15. Black RE, Allen LH, Bhutta ZA, Caulfield LE, De Onis M, Ezzati M, et al. Maternal and Child Undernutrition Study Group. Maternal and child undernutrition: global and regional exposures and health consequences. The Lancet. 2008;371(9608):243-60.

16. Babatunde RO, Qaim M. Impact of off-farm income on food security and nutrition in Nigeria. Food Pol. 2010;35(4):303-11.

17. Girma W, Genebo T. Determinants of nutritional status of women and children in Ethiopia. Maryland: ORC Macro; 2002.

18. Nair KRG. Malnourishment among children in India: A regional analysis. Econ. Political Wkly. 2007:3797-803.
19. Giroux SC. Child stunting across schooling and fertility transitions: Evidence from sub-Saharan Africa. Dem. and Health Res. 2008; 57(4):2-5.

20. Alderman H, Hentschel J, Sabates, R. With the help of one's neighbours externalities in the production of nutrition in Peru. Soc. Sc. Med. 2003;56(10): 20192031.

21. Charmarbagwala $\mathrm{R}$, Ranger $\mathrm{M}$, Waddington $\mathrm{H}$, White H. The determinants of child health and nutrition: a meta-analysis. Washington, DC: World Bank; 2004.

22. Kumi-Kyereme A, Amu H, Darteh EK. Barriers and motivations for health insurance subscription in Cape Coast, Ghana: a qualitative study. Arch. Pub. Health. 2017;75:24.

23. Amu H, Dickson KS. Health insurance subscription women in reproductive age in Ghana: do sociodemographics matter? Health Econs. Rev. 2016;6:24.

Copyright (C) The Author(s). This is an Open Access article under the CC BY license. 